\title{
$\angle$ Research Square \\ Delivery service satisfaction and associated factors among mothers who gave birth at West Shewa Zone public hospitals, Ethiopia
}

Nagasa Dida ( $\square$ nadibefe@yahoo.com )

Ambo University https://orcid.org/0000-0002-9105-8122

\section{Getu Bayissa}

Ambo University

Habtamu Oljira

Ambo University

Kefyalew Taye

Ambo University

\section{Research article}

Keywords: Delivery service, satisfaction, mothers, Ethiopia

Posted Date: September 8th, 2019

DOl: https://doi.org/10.21203/rs.2.14145/v1

License: (우 This work is licensed under a Creative Commons Attribution 4.0 International License. Read Full License 


\section{Abstract}

Objective: This study assessed mothers satisfaction towards delivery Services and its associated factors at public Hospitals found in West Shewa Zone, Ethiopia, from March 1 to April 15/2018. Result : This study finding showed that the overall satisfaction level of mothers towards delivery service was $82.1 \%$. Those Mother's who planned their pregnancy were 4.93 times more satisfied with delivery service than those who did not planned (AOR: $4.93 ; 95 \% \mathrm{Cl}: 2.172-11.208)$. The odds of satisfaction for women who had pain management were 1.56 times higher than those who did not. Moreover, Gestational age at birth for pre-term and full term [(AOR: $0.027 ; 95 \% \mathrm{Cl}: 0.003-0.254)$, (AOR: $0.067 ; 95 \% \mathrm{Cl}: 0.011-0.401)$ ], means of transportation (use of Ambulance) (AOR: 3.785; 95\% Cl: 1.24-11.51) and stay in hospital (AOR: 0.10, 95\% Cl 0.01, 0.93) were the significant predictors of mother's satisfaction with delivery service at the study area. Therefore notable attention should be given to those factors as they may influence the future utilization of service.

\section{Introduction}

Sub-Saharan Africa countries are characterized by high maternal mortality ratio and lowest coverage of births attended by skilled health care provider[1]. Ethiopia is also one of the Sub-Saharan African countries(SSA) with high maternal mortality ratio of 412 per 100,000 live births and 19,000 maternal deaths annually[2].This is due to delays in seeking health service, in reaching the health facility and in receiving timely and effective intervention after reaching the health facility[3].

Worldwide, $63.1 \%$ of births were attended by a skilled health care provider. Almost all births were attended by skilled health care professionals in developed countries. In Africa and Asia, only $46.5 \%$ and $60.8 \%$, respectively, of women gave birth with the help of a skilled attendant [4]. In Ethiopia, only about $28 \%$ of deliveries were attended by a skilled birth attendants and only about $26 \%$ of delivery was institutional. On contrary, home delivery was $73 \%$ which is still high. Similarly, in Oromia region (Ethiopia) Home delivery accounts $81 \%$ while institutional deliveries was only about $19 \%[1,5,6]$.

Low utilization of delivery service at health facility was mainly related to maternal satisfaction during delivery services [7, 8]. That's why WHO emphasizes ensuring client satisfaction as a means of secondary prevention of maternal mortality, since satisfied women are more likely to adhere to health care providers recommendations and utilization[9].

The magnitude of maternal satisfaction on delivery care varies across countries: $67.8 \%$ in Nepal, $56 \%$ in Nairobi (Kenya), 19\% at Saint Paulos Hospital (Ethiopia), 80.7\% at Asella Hospital (Ethiopia) [10-13] .

Maternal satisfaction with hospital care during delivery plays a role in utilization of maternal health services [14]. It improves client friendliness, cultural sensitivity of institution based delivery and postpartum care[15].Women who were satisfied with delivery care have better self-esteem and confidence, faster in establishing a maternal-neonatal bond, and more likely to breastfeed their infant $[16,17]$.

Studies had shown that, women who were dissatisfied with their delivery experiences were more prone to develop a fear of delivery, postnatal depressive symptoms, face difficulties in breastfeeding and in performing self-care and their new born $[18,19]$. Furthermore, it may also resulted with poorer postnatal psychological 
adjustment, a higher rate of future abortions, preference for a caesarean section, more negative feelings towards the infant and breast-feeding problems[20].

In Ethiopia few studies were conducted, meanwhile all studies were quantitative which prevent mothers from expressing their deepest feeling about delivery service they had provided. Therefore using both quantitative and qualitative methods, this study aimed to assess the current status of mother's satisfaction towards delivery services and its associated factor at the study area.

\section{Methods}

\section{Study design and setting}

Institutional based cross sectional study supplemented by qualitative method was conducted from March 1 to April 15, 2018 at West Shewa zone public Hospitals, Ambo Ethiopia. Ambo town, the administrative center of West Shewa Zone, located at $114 \mathrm{Km}$ to the west of Addis Ababa, capital city of Ethiopia. According to national population and housing census of 2007, the projected population of the Zone for 2018 was estimated to be $2,607,827.00$ among which 1.3 million were women and 89,133 pregnant mothers [21].

\section{Sample size determination and Sampling procedures}

All randomly selected mothers who gave birth in selected Hospitals during the study period were included in the study. Single population proportion formula was used to get final sample size of 390 , at $95 \%$ confidence level, $5 \%$ marginal error, $10 \%$ non-response rate, 1.5 design effect and $19 \%$ level of satisfaction taken from previous study [17]. Moreover, for in-depth interview, ten participants ( 6 mothers who gave births and 4 family members) were selected purposively from selected hospitals.

\section{Data collection methods}

For Quantitative part: Data were collected using a pre tested Interviewer administered structured questionnaire. The questionnaire were adapted by reviewing related studies and presented using a 5-scale or likert scale measurements (1-very dissatisfied, 2-dissatisfied, 3-neutral, 4-satisfied and 5-very satisfied). Questions were prepared originally in English language and then translated to local language for easy management, then translated back to English to maintain the quality and consistency of information. The overall level mother's satisfaction was calculated from 20 items of satisfaction questions; which reported a good internal consistency (Cronbach \s alpha $=0.76)$.

For qualitative part: In-depth interview was employed on mothers who gave birth at selected hospital and their family or supporter during the study period. However, those mothers who participated in quantitative study were excluded from participating in interviews.

\section{Data analysis procedures}


Quantitative data analysis: Collected data were cleaned, coded and entered to Epi-data version 3.1 and exported to SPSS version 20 windows for further analysis. Bivariate and multivariable logistic regression was performed. Independent variables with p-value $<0.2$ in bivariate logistic regression were included for multivariable logistic regression. Variables were considered as statistically significant if $p$-value $<0.05$ in multivariable logistic regression.

Qualitative data analysis: Collected data were transcribed and translated exactly from local language to English. The manual transcription and thematic content analysis was conducted. Then identified themes were triangulated with quantitative part to determine differences and similarities in the perspectives of the mother's satisfaction on delivery service.

\section{Results}

\section{Socio-demographic characteristics of the respondents}

A total of 390 mothers were participated in this study making $100 \%$ response rate. The mean age of the respondents was $26.92 \pm 5.10 \mathrm{SD}$. About $322(82.6 \%)$ of delivery were planned, about $123(59.9 \%)$ mothers came to hospitals using Ambulance whereas 297(76.3\%) of them waited care provider for $<15$ minutes (Table 1).

\section{Factors associated with delivery service satisfaction}

After controlling for the effects of potentially confounding variables using multivariable logistic regression, gestational age preterm and full term [(AOR: $0.027 ; 95 \%$ Cl: 0.003-0.254), (AOR: 0.067; $95 \%$ Cl: 0.011-0.401)] respectively, ambulance use (AOR:3.785; 95\% Cl: 1.24-11.51)., planned pregnancy (AOR: 4.93; 95\% Cl: 2.17211.208), duration of hospital stay (AOR: $0.10,95 \% \mathrm{Cl} 0.01,0.93$ ) and given medication for pain management (AOR: $4.782,95 \% \mathrm{Cl}: 1.98-10.52$ ) were variables that predict delivery service satisfaction among mothers who gave birth at the study area (Table 2).

\section{Discussion}

The study revealed that, the overall delivery service satisfaction of mothers was $82.1 \%$. This finding is comparable with studies conducted at Serbian public Hospitals (81\%), Wolaita Hospital, Ethiopia (82.3\%), Assela hospital Ethiopia (80.7\%), Gamo-Gofa Zone, South Ethiopia (79.1\%) and Debremarkos Hospital, North west Ethiopia $81.7 \%$ [22-26].This may be due to similarities of these hospitals by patient load, number of health professionals and infrastructures.

However, the findings of this study is higher than the studies done in western Nepal, Northern

Jordan, Kenya, Felege Hiwot Referral hospital (Ethiopia) and St.paulose hospital (Ethiopia) which were 67.8\%, $64 \%, 56 \%, 74.9 \%$ and $19 \%$ respectively $[8,10-12,18]$. This variation may be due to difference back ground of the study participants, satisfaction measurement tools used, study time difference, method of analysis. On 
the other hand, this finding is lower than studies conducted in west India $(86 \%)$ and Kenya $(96 \%)[27,28]$. This discrepancy may be due to cultural difference and difference in quality of service provided at this study area.

This study revealed variables like: gestational age at birth, duration of stay, mode of transportation (use of free Ambulance), fetal outcome, status of pregnancy and pain managements were predictor's of delivery service satisfaction among study participants. This finding is consistent with other studies conducted at different part of Ethiopia [10, 12, 28, 29]. Likewise, Mothers who gave birth at preterm and full term were less satisfied than those who gave birth at post term (AOR: 0.027, 95\% Cl: 0.003- 0.25), AOR: 0.067, 95\% Cl: 0.01 0.40 ) respectively. However, this finding was found in contrast with the finding from a Nepal study [10]. The reason may be due to difference in expectation of mothers and cultural difference.

Additionally duration of stay in hospital was other predictor of delivery service satisfaction. Mothers who stayed in hospitals for 48-72 hours were less satisfied compared to those who stayed $>72$ hours (AOR:0.107,95\% Cl: 0.01-0.93). This finding was in contrast with studies conducted at Nepal and St Paul's hospital[10,12]. The possible reason could be mother's perception of getting a better care through longer stay in hospitals.

The other important predictor of delivery service satisfaction was means of transportation. Mothers who came to hospital during their labor by free Ambulance were 3.785 times more likely to be satisfied than those who used other means of transportation like by cart, on foot by shoulder (AOR:3.785,95\% Cl: 1.24 - 11.51). It is supported by qualitative study. "... The existence of ambulance was unforgettable for its contribution in my arrival very quickly...". Nevertheless, means of transportation was not statically associated with maternal satisfaction with delivery service[24] .The possible reason may due to different in topography of the study area and accessibility of Hospitals and awareness of study participant on use of ambulance.

Regarding the status of mothers pregnancy, mothers who planned their pregnancy were 4.93 times more satisfied with delivery care than those who did not planned (AOR: $4.93,95 \% \mathrm{Cl} ; 2.17-11.20$ ). This finding is similar with studies conducted at Kenya, Amhara region referral hospitals and Jimma zone, Ethiopia [11, 29, 30].This may due to having planned pregnancy may be associated with better psychological preparation for the delivery service.

Lastly pain management was significantly associated with delivery service satisfaction. These mothers who get medication for pain management were 4.5 times more likely to be satisfied as compared to who did not (AOR: 4.782; 95\% Cl: 1.98 - 10.52). This result is in line with studies conducted elsewhere[25, 29, 31], as well as supported by qualitative result which states "When they were stitching up the episiotomy site they gave me anti- pain and I felt much better." Similarly another mother reported "I cannot tolerate its pain and I shouted to them if anything is their which can reduce it. Then they gave me one injection and I became better."

In this study variables like: income, residence, ethnicity, ANC follow up and Educational status of the respondents were not significantly associated with delivery service satisfaction as it was explained in previous studies $[8,12,25,27]$.

\section{Limitation of the study}


The nature of the study does not allow the study to establish causal relationship between the different independent variables and the dependent variable.

\section{Abbreviations}

ANC: Anti natal care; AOR: Adjusted odds ratio; Cl: Confidence Interval; COR: Crude odds ratio; SSA: SubSaharan Africa

\section{Declarations}

\section{Ethics approval and consent to participate}

Ethical clearance was obtained from Ambo University College of Medicine Health Science ethics review board with the Ref. Number of: RMHS-ERC: 32/2010 and project number: CMHS: 008/18. The nature of the study was explained to the study participants and written informed consent was obtained prior to participation in the study. Privacy and confidentiality of collected information was ensured.

\section{Consent to publish}

Not applicable

\section{Availability of data and materials}

All data that support the findings of this study is available from the corresponding author upon request.

\section{Competing interests}

The authors declare that they have no competing interests.

\section{Funding}

No fund received from any funding organizations.

\section{Authors' contributions}

GB involved in conception, design of study, data collection, analysis and final report writing. ND and HO participated on supervision and guidance of the work. KT has prepared the manuscript for publication. Finally all authors have proof read the final manuscript.

\section{Acknowledgements}


Our special gratitude goes to Ambo University, Department of Public Health and West Shoa Zone Public Hospitals for all their priceless supports. Finally we would like to appreciate supervisors, data collectors and study participants.

\section{References}

1.Organization, W. H., Trends in maternal mortality: 1990-2015: estimates from WHO, UNICEF, UNFPA, World Bank Group and the United Nations Population Division: executive summary. 2015, World Health Organization.

2.CSA, I., Ethiopia demographic and health survey 2011. Addis Ababa, Ethiopia and Calverton, Maryland, USA: Central Statistical Agency and ICF International, 2012. 430.

3.Ethiopian Public Health Institute, National MDSR Annual Report 2008 Ethiopian Fiscal Year. 2017.

4.Organization, W. H., Proportion of births attended by Skilled Health Worker 2008 updates. 2008.

5.Mengesha, Z. B., et al., Determinants of skilled attendance for delivery in Northwest Ethiopia: a community based nested case control study. BMC Public Health, 2013. 13(1): p. 130.

6.Tarekegn, S. M., L. S. Lieberman, and V. Giedraitis, Determinants of maternal health service utilization in Ethiopia: analysis of the 2011 Ethiopian Demographic and Health Survey. BMC pregnancy and childbirth, 2014. 14(1): p. 161.

7.Emelumadu, O. F., et al., Perception of quality of maternal healthcare services among women utilising antenatal services in selected primary health facilities in Anambra State, Southeast Nigeria. Nigerian medical journal: journal of the Nigeria Medical Association, 2014. 55(2): p. 148.

8.Mekonnen, M. E., W. A. Yalew, and Z. A. Anteneh, Women's satisfaction with childbirth care in Felege Hiwot Referral Hospital, Bahir Dar city, Northwest Ethiopia, 2014: cross sectional study. BMC research notes, 2015. 8(1): p. 528.

9.Organization, W. H. and Unicef, Trends in maternal mortality: 1990 to 2013: estimates by WHO, UNICEF, UNFPA, The World Bank and the United Nations Population Division. 2014.

10.Regmi, S., H. P. Kaphle, and N. Gupta, Maternal satisfaction regarding perinatal care and Influencing factors in tertiary hospitals of western, Nepal. Medicine, 2017. 6(3): p. 471-75.

11.Bazant, E. S. and M. A. Koenig, Women's satisfaction with delivery care in Nairobi's informal settlements. International Journal for Quality in Health Care, 2009. 21(2): p. 79-86.

12.Demas, T., et al., Women's satisfaction with intrapartum care in St Paul's Hospital Millennium Medical College Addis Ababa Ethiopia: a cross sectional study. BMC pregnancy and childbirth, 2017. 17(1): p. 253.

13.MesfinTafa, R., Maternal Satisfaction with the Delivery Services in Assela Hospital, Arsi Zone, Oromia Region, Ethiopia, 2013. Gynecol. Obstetrics, 2014. 4: p. 12. 
14.Bernitz, S., et al., Evaluation of satisfaction with care in a midwifery unit and an obstetric unit: a randomized controlled trial of low-risk women. BMC pregnancy and childbirth, 2016. 16(1): p. 143.

15.Chanza, D., et al., Factors affecting the choice for home deliveries in Malawi. African Journal of Midwifery and Women's Health, 2012. 6(3): p. 125-130.

16.Leap, N., et al., Journey to confidence: women's experiences of pain in labour and relational continuity of care. The Journal of Midwifery \& Women's Health, 2010. 55(3): p. 234-242.

17.Meleis, A. I., Transitions theory: Middle range and situation specific theories in nursing research and practice. 2010: Springer publishing company.

18.Mohammad, K., et al., J ordanian women's dissatisfaction with childbirth care. International Nursing Review, 2014. 61(2): p. 278-284.

19.Hegde, S., et al., Postpartum depression: prevalence and associated factors among women in India. Journal of Women's Health, Issues and Care, 2012. 1(1): p. 1-7.

20.Shakibazadeh, E., et al., Respectful care during childbirth in health facilities globally: a qualitative evidence synthesis. BJOG: An International Journal of Obstetrics \& Gynaecology, 2018. 125(8): p. 932-942.

21. West Shoa Zonal Health Department, Annual Plan and Report. 2017.

22.Matejić, B., et al., Maternal satisfaction with organized perinatal care in Serbian public hospitals. BMC pregnancy and childbirth, 2014. 14(1): p. 14.

23. Yohannes, B., M. Tarekegn, and W. Paulos, Mothers' utilization of antenatal care and their satisfaction with delivery services in selected public health facilities of wolaita zone, Southern Ethiopia. International journal of scientific \& technology research, 2013. 2(2): p. 74-85.

24.Tesfaye, R., et al., Client satisfaction with delivery care service and associated factors in the public health facilities of Gamo Gofa Zone, southwest Ethiopia: in a resource limited setting. Obstetrics and gynecology international, 2016. 2016.

25.Amdemichael, R., M. Tafa, and H. Fekadu, Maternal satisfaction with the delivery services in Assela Hospital, Arsi zone, Oromia region. Gynecol Obstet (Sunnyvale), 2014. 4(257): p. 2161.

26.Bitew, K., M. Ayichiluhm, and K. Yimam, Maternal satisfaction on delivery service and its associated factors among mothers who gave birth in public health facilities of Debre Markos Town, Northwest Ethiopia. BioMed research international, 2015. 2015.

27.Mishra, S. and J. Macwana, client's perspective on obstetric care received at $24 x 7$ primary health centers of a district located in western India. Innovative J Med Health Sci, 2013. 3(3): p. 136-9.

28.Okumu, C. and B. Oyugi, Clients' satisfaction with quality of childbirth services: a comparative study between public and private facilities in Limuru Sub-County, Kiambu, Kenya. PloS one, 2018. 13(3): p. 
e0193593.

29.Melese, T., et al., Assessment of client satisfaction in labor and delivery services at a maternity referral hospital in Ethiopia. The Pan African medical journal, 2014. 17.

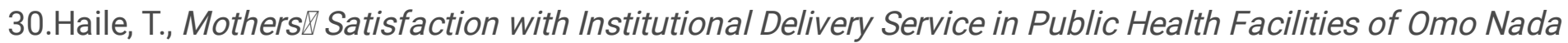
District, Jimma Zone. Clin. Med. Res, 2017. 6(1): p. 23.

31.Naghizadeh, S., et al., Assessing the factors of mother's dissatisfaction with labor and delivery care procedure in educational and non-educational hospitals in Tabriz. European Journal of Experimental Biology, 2013. 3(6): p. 132-9.

\section{Tables}

Table 1: Characteristics of mothers who gave birth at West Shoa Zone public Hospitals Ambo, Ethiopia, $2018(n=390)$ 


\begin{tabular}{|c|c|c|c|}
\hline Characteristics & Category & Freq & Percent (\%) \\
\hline Age (year) & $<20$ & 17 & 4.4 \\
\hline & $20-34$ & 331 & 84.9 \\
\hline & $35-41$ & 42 & 10.7 \\
\hline Marital status & Single & 26 & 6.7 \\
\hline & Married & 332 & 85.1 \\
\hline & Divorced & 12 & 3.1 \\
\hline & Widowed & 20 & 5.1 \\
\hline Educational status & Unable to read \& write & 88 & 22.6 \\
\hline & Primary school & 125 & 32.1 \\
\hline & Secondary school & 102 & 26.1 \\
\hline & Certificate and above & 75 & 19.2 \\
\hline Parity & 1child & 86 & 22.1 \\
\hline & 2-4 children & 250 & 64.1 \\
\hline & $\geq 5$ children & 54 & 13.8 \\
\hline ANC follow up & Yes & 356 & 91.3 \\
\hline & No & 34 & 8.7 \\
\hline Status of pregnancy & Planned & 322 & 82.6 \\
\hline & Unplanned & 68 & 17.4 \\
\hline Mode of delivery & SVG & 280 & 71.8 \\
\hline & \begin{tabular}{|l|} 
Assisted delivery \\
\end{tabular} & 66 & 16.9 \\
\hline & Caesarian section & 44 & 11.3 \\
\hline & $<12$ hours & 227 & 58.2 \\
\hline Duration of labor & $>=12$ hours & 163 & 41.8 \\
\hline & Normal & 349 & 89.5 \\
\hline Maternal out come & With complication & 41 & 10.5 \\
\hline Fetal outcome & \begin{tabular}{|l|} 
Normal \\
\end{tabular} & 380 & 97.4 \\
\hline & Died & 10 & 2.6 \\
\hline Gestation age at birth & Preterm & 14 & 3.6 \\
\hline & Full term & 333 & 85.4 \\
\hline & Post term & 43 & 11.0 \\
\hline Mode of transportation & Public car & 124 & 31.5 \\
\hline & Ambulance & 233 & 60 \\
\hline & Cart/shoulder/on foot & 33 & 8.5 \\
\hline Waiting time & $<15$ minute & 298 & 76.4 \\
\hline & 15-30minute & 86 & 22.1 \\
\hline & 30-60minute & 6 & 1.5 \\
\hline Medication for pain manageme & Yes & 192 & 49 \\
\hline & No & 198 & 51 \\
\hline
\end{tabular}

SVG=shows spontaneous vaginal delivery

Table 2: Multivariable logistic regression analysis of factors associated with delivery ser satisfaction among mothers who gave birth at West Shoa Zone public Hospitals Ambo, Ethio $2018(n=390)$ 


\begin{tabular}{|c|c|c|c|c|c|}
\hline \multirow[t]{2}{*}{ Variables } & \multicolumn{2}{|c|}{ Satisfaction } & \multirow[t]{2}{*}{ COR(95\% CI) } & \multirow[t]{2}{*}{ AOR(95\% CI) } & \multirow[t]{2}{*}{$\begin{array}{l}\mathrm{P} \\
\text { value }\end{array}$} \\
\hline & Dissatisfie & Satisfied & & & \\
\hline \multicolumn{6}{|l|}{ Age } \\
\hline$<20$ & $9(2.31)$ & $8(2.05)$ & $0.178(.051-.62)$ & $.118(.007-1.917)$ & 0.322 \\
\hline $20-34$ & $54(13.85)$ & 277(71.03) & $1.026(.43-2.43)$ & $.750(.237-2.375)$ & 0.133 \\
\hline $35-41$ & $7(1.79)$ & $35(8.97)$ & & 1.00 & 0.624 \\
\hline \multicolumn{6}{|l|}{ Status of pregnancy } \\
\hline Planned & $45(11.54)$ & $277(71.03)$ & $3.57(1.99-6.42)$ & $4.93(2.17-11.20)$ & \begin{tabular}{|l|}
$.000 \dagger$ \\
\end{tabular} \\
\hline Unplanned & $25(6.41)$ & $43(11.03)$ & 1.00 & 1.00 & \\
\hline \multicolumn{6}{|l|}{ Gestational age } \\
\hline Preterm & $7(1.79)$ & $7(1.79)$ & $.04(.008-0.285)$ & $.027(.003,0.254)$ & \begin{tabular}{|l|}
$.002 \dagger$ \\
\end{tabular} \\
\hline Full term & $61(15.64)$ & $272(69.74)$ & $.21(.051-0.92)$ & $.067(.011,0.401)$ & $.003 \dagger$ \\
\hline Post term & $2(0.5)$ & $41(10.51)$ & 1.00 & 1.00 & \\
\hline \multicolumn{6}{|l|}{ Pain management } \\
\hline Yes & $16(4.10)$ & 176(41.13) & $4.13(2.2-7.5)$ & $\begin{array}{l}4.57(1.98- \\
10.52)\end{array}$ & $0.00^{*}$ \\
\hline No & $54(13.85)$ & $144(36.92)$ & 1.00 & 1.00 & \\
\hline \multicolumn{6}{|l|}{ Mode of transport } \\
\hline & & & & & .032 \\
\hline Public transport & $30(7.69)$ & $98(25.13)$ & $1.99(.77-4.169) \dagger$ & $\begin{array}{l}1.58(0.58 \\
-.5 .47)\end{array}$ & 0.310 \\
\hline Ambulance & $29(7.44)$ & 202(51.77) & $3.83(1.66-8.80)$ & $\begin{array}{l}3.78(1.2- \\
11.52)\end{array}$ & $0.019 *$ \\
\hline Others & $11(2.82)$ & $20(5.13)$ & 1.00 & 1.00 & \\
\hline $\begin{array}{l}\text { Duration of stay in } \\
\text { Hospital }\end{array}$ & & & & & .072 \\
\hline$<24$ hrs & $44(11.28)$ & 202(51.79) & $.306(.07-1.32)$ & $0.368(.05-2.49)$ & 0.306 \\
\hline 24-48hrs & $17(4.36)$ & $68(17.44)$ & $.267(.05-1.22)$ & $0.176(0.03-$ & 0.082 \\
\hline $48-72 \mathrm{hrs}$ & $7(1.79)$ & $20(5.13)$ & $.19(.03-1.01)$ & $\begin{array}{l}0.107(.012- \\
0.93)\end{array}$ & 0.043 \\
\hline$>72 \mathrm{hrs}$ & $2(0.51)$ & $30(7.69)$ & 1.00 & 1.00 & \\
\hline
\end{tabular}

* Statistically significant at $p$ value $\leq 0.05,1$ for reference population 